\title{
Abordagem multiprofissional na Doença de Krabbe: relato de caso
}

\author{
Multiprofessional approach in Krabbe Disease: case report
}

\section{Enfoque multiprofesional en la Enfermedad de Krabbe: caso clínico}

\author{
Karini Martins Limaํ, Daniela Maria Silva Maia², Jean Carlos de \\ Oliveira Menezes ${ }^{3}$, Jessica Bruna Florência e Silva ${ }^{4}$, \\ Joelma Gomes da Silva ${ }^{5}$
}

\begin{abstract}
1.Faculdade filiada: Faculdade do Vale do Jaguaribe, Aracati-CE, Brasil. ORCID: https://orcid.org/00000001-7364-0373

2.Faculdade filiada: Faculdade do Vale do Jaguaribe, Aracati-CE, Brasil. ORCID: https://orcid.org/00000002-1724-2124

3.Faculdade filiada: Faculdade do Vale do Jaguaribe, Aracati-CE, Brasil. ORCID: https://orcid.org/00000002-1236-7892

4.Faculdade filiada: Faculdade de Enfermagem Nova Esperança, Mossoró-RN, Brasil. ORCID: https://orcid.org/0000-0001-8227-1944

5. Faculdade Filiada: Faculdade de Enfermagem Nova Esperança, Mossoró-RN, Brasil. ORCID: https://orcid.orq/0000-0001-7088-6191
\end{abstract}

\section{Resumo}

A doença de Krabbe é uma doença neurodegenerativa autossômica recessiva ocorrida por uma mutação do cromossomo 14q31.3. Diante disto, o objetivo deste trabalho foi descrever um caso de um paciente com Doença de Krabbes submetido a um tratamento multiprofissional. Até os 4 meses a criança apresentou seu desenvolvimento motor normal e logo após apareceu os primeiros sintomas. Aos 8 meses recebeu o diagnóstico e permaneceu até os 5 anos e 2 meses em atendimento domiciliar com acompanhamento de equipe Multiprofissional. Durante esse período apresentou-se estável, sem complicações e his tórico de internações, ressaltando a relevância desse acompanhamento na sobrevida desses pacientes.

Unitermos. Doença de Krabbe; Leucodistrofia das Células Globoides; Fisioterapia; Terapia respiratória; Equipe Multiprofissional

\begin{abstract}
Krabbe's disease is an autosomal recessive neurodegenerative disease caused by a mutation of chrom osome 14q31.3. In view of this, the objective of this study was to describe a case of a patient with Krabbes disease who underwent multiprofessional treatment. Until the age of 4 months, the child showed normal motor development and soon after the first sym ptoms appeared. At 8 months he received the diagnosis and remained until 5 years and 2 months in home care with monitoring by a Multiprofeonal team. During this period, he was stable, without complications and with a history of hospitalizations, emphasizing the relevance of this monitoring in the survival of these patients.
\end{abstract}

Keywords. Krabbe Disease; Leukodystrophy of Globular Cells; Physical therapy; Respiratory therapy; Multiprofessional Team

\section{Resumen}

La enfermedad de Krabbe es una enfermedad neurodegenerativa autosómica recesiva causada por una mutación del cromosoma 14q31.3. En vista de esto, el objetivo de este estudio fue describir un caso de un paciente con enfermedad de Krabbes que se sometió a un tratamiento multiprofesional. Hasta la edad de 4 meses, el niño mostró un desarrollo motor normal y poco después aparecieron los primeros síntomas. A los $8 \mathrm{~m}$ eses recibió el diagnóstico y permaneció hasta 5 años y 2 meses en atención domiciliaria con monitoreo por 
un equipo multiprofesional. Durante este período, se mantuvo estable, sin complicaciones y con antecedentes de hospitalizaciones, destacando la relevancia de este monitoreo en la supervivencia de estos pacientes.

Palabras clave: enfermedad de Krabbe; Leucodistrofia de células globoides; Fisioterapia; Terapia respiratoria; Equipo multiprofesional

Trabalho realizado na Faculdade do Vale do Jaguaribe, Aracati-CE, Brasil

Endereço para correspondência: Joelma G Silva. R José Nolasco de Souza, 10. Rincão. Mossoró-RN, Brasil. CEP 59630-510. Fone: (84)99930-0943. E-mail: fisiojoelmagomes@gmail.com

\section{INTRODUÇÃO}

A Leucodistrofias das Células Globo

ides (LCG) ou Doença de Krabbe (DK) foi descrita em 1916, pelo neurologista Knud Haroldsen Krabbe, que apresentou cinco crianças com algumas características neuropatológicas, manifestando uma esclerose difusa no cérebro ${ }^{1,2}$.

Atualmente é caracterizada como uma doença neurodegenerativa autossômica recessiva, extremamente rara, com incidência estimada em 1:100.000 nascidos vivos; ocorrida por uma deficiência na função da enzima lisossomal galactosilceramidase (galactocerebrosidase GALC) por mutação no gene do cromossomo 14q31.3. Essa enzima é um elemento fundamental durante o período perinatal, especialmente importante até aproximadamente os 18 meses de vida, sendo responsável pela hidrólise das ligações éster da galactose de galactoesfingolipídeos, tais como galactosilceramida e galactosilesfingosina (psicosina), presentes na membrana da mielina ${ }^{3}$. 
Pode ser classificada como: infantil precoce, que corresponde a 85-90\% dos casos; infantil tardia; juvenil e adulto. Os sintomas apresentados são: espasticidade, irritabilidade e atraso durante o desenvolvimento motor, podendo, assim, causar a morte antes dos dois anos de vida. Sendo necessário o conhecimento do quadro clínico para investigação diagnóstica ${ }^{4,5}$.

Portanto, diante dessa realidade, esta pesquisa teve como objetivo descrever um caso de um paciente com DK.

\section{RELATO DO CASO}

Trata-se de um estudo de caso aprovado no comitê de ética e pesquisa da Faculdade Pitágoras - Fortaleza/CE. Número do protocolo: 3.929.206.

Paciente, sexo masculino, no momento da pesquisa estava com 4 anos e 11 meses, pré-termo, parto cesáreo, sem intercorrências no período gestacional e pós-parto imediato. Segundo relato da genitora, a criança apresentou aquisições motoras durante os primeiros 4 meses de vida, com respostas aos reflexos primitivos; capacidade de acompanhar movimentos com os olhos; sorrir aos estímulos auditivos, sustentar e controlar a cabeça. Após completados 4 meses, surgiram os primeiros sinais: olhar fixo, choro incontrolável, irritabilidade e espasmos musculares em membros superiores. A partir disto, começou a fazer uso do fenobarbital e então só manifestava reações a estímulos dolorosos. Neste mesmo 
período houve comprometimento da independência e funcionalidade, porém sem histórico de hospitalizações.

Aos cinco meses de idade foi realizado o Eletroencefalograma (EEG) que apontou presença de ondas delta e teta, lentas, esparsas e generalizadas em surtos. Logo após o resultado, a criança foi encaminhada para internação sendo admitido na Unidade de Terapia Intensiva e posteriormente seguindo para a Unidade de Pacientes Especiais, onde ficou um ano e três meses. Durante este período foi submetido a vários exames, até chegar ao ensaio enzimático: arisulfatase A $(6,1 \mathrm{nmol} / \mathrm{h} / \mathrm{mg}$ proteína/valor de referência: 5-20); e galactocerebrosidase (2,4nmol/h/mg proteína/valor de referência: 14-53); diagnóstico bioquímico da DK concluído aos 8 meses de idade.

Desde então, a criança ficou sendo acompanhada pelo Programa de Assistência Ventilatória Domiciliar com visita de uma equipe Multiprofissional composta por médica pediatra a cada 15 dias, fisioterapeuta duas vezes por semana e enfermeira 1 vez por semana.

A Pediatra acompanhava o quadro clínico; a enfermeira entregava equipamentos e realizava orientações sobre cuidados diários. Já a Fisioterapeuta realizava atendimentos voltados para o sistema respiratório e motor da criança.

$\mathrm{Na}$ avaliação inicial da Fisioterapeuta, o paciente apresentava de acordo com a Escala de Coma de Glasgow ECG: Abertura ocular 4 (espontâneo); Resposta verbal 1 
(ausente); Resposta motora: flexão anormal 3, extensão anormal 2, totalizando um score de 10 pontos. Na Escala de Sedação de Ramsay apresentou grau 4 (sedado, com resposta rápida a leve toque entre as sobrancelhas (glabela) ou estímulo auditivo alto). Na avaliação cinético funcional apresentou grau de força muscular 1 para todos os movimentos de membros superiores e inferiores.

$\mathrm{Na}$ avaliação respiratória a criança encontrava-se em uso de Ventilação Mecânica Invasiva (VMI); apresentando na ausculta pulmonar: murmúrio vesicular presente com roncos difusos; padrão respiratório normal, tórax simétrico e com boa amplitude dos movimentos respiratórios e ausência do reflexo de tosse.

A Fisioterapia motora teve como objetivo prevenir contraturas e deformidades no sistema osteomioarticular. 0 tratamento incluiu exercícios de dissociação de tronco, mudanças de decúbito, alongamentos, dissociação de cinturas, exercícios passivos nos membros, posicionamento em posturas extensoras em membros superiores e orientações sobre posicionamento.

A fisioterapia respiratória teve como objetivo manter as vias aéreas limpas e pérvias para diminuir os riscos de infecções e a necessidade de hospitalizações. No decorrer dos atendimentos, utilizou-se o ambu associado com soro fisiológico, juntamente com as técnicas de higiene brônquica, tais como: vibro compressão, compressão/descompressão, Aceleração de Fluxo Expiratório (AFE) e aspiração das vias aéreas superiores. 
Desde então o quadro geral da criança apresentou-se estável, sem deformidades significativas (Figura 1) e registro de internações.

Alguns meses após esse estudo o paciente faleceu aos 5 anos e 2 meses de idade por parada cardiorrespiratória.

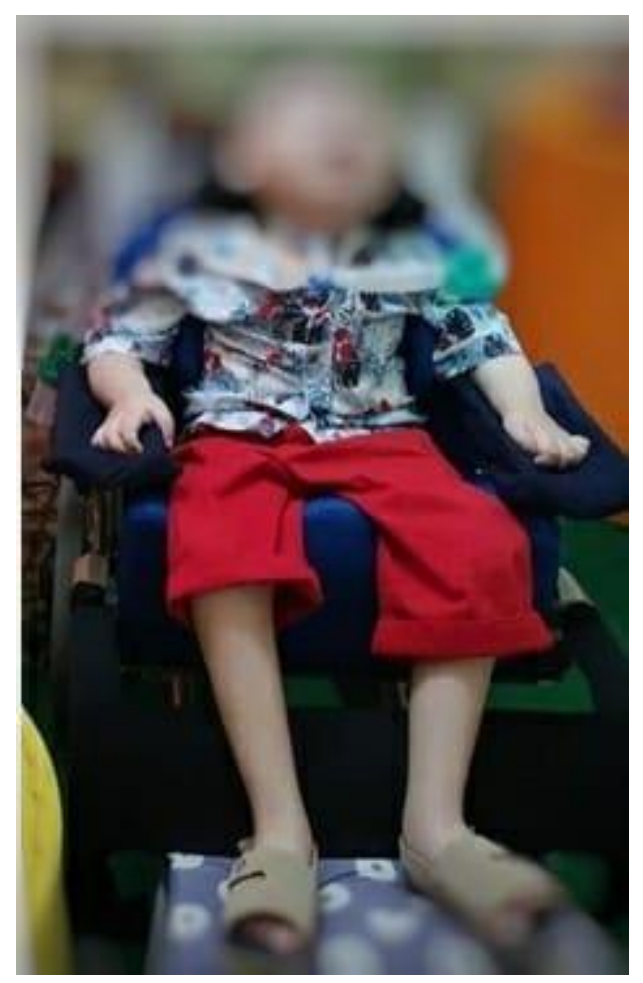

Figura1. Criança com cinco anos de idade (com autorização dos responsáveis).

\section{DISCUSSÃO}

As crianças com DK do tipo infantil precoce, desenvolvem aquisições motoras nos primeiros meses de $v^{v i d a}{ }^{6}$, e as manifestações clínicas ocorrem antes dos 6 primeiros meses $^{5}$, com dificuldades de alimentação, atrasos no desenvolvimento motor, cegueira e surdez, convulsões e 
deterioração mental ${ }^{3}$, culminando com os sinais clássicos de choro excessivo, extrema irritabilidade, presente em todas as crianças diagnosticadas; e espasticidade muscular ${ }^{2,4}$.

O diagnóstico é fundamentado através da história familiar, quadro clínico e exames genéticos com avaliação da função da atividade da enzima GALC em recém-nascidos e dosagem da atividade desta enzima nos leucócitos isolados que apresenta valores menores que $15 \mathrm{nmol} / \mathrm{h} /$ proteína $^{4,5}$, sendo que a atividade encontrada foi de 2,4nmol/17h/mg proteína (valor de referência: 14-53).

Geralmente esses pacientes saem do ambiente hospitalar com o intuito de evitar possíveis infeções, porém continua restrito ao leito sendo fundamental o acompanhamento da equipe multiprofissional. Sobre isto, a intervenção fisioterapêutica é a mais frequente com objetivo de diminuir a degeneração muscular através de recursos que auxiliem na prevenção de contraturas, controle da espasticidade, melhora da mobilidade, flexibilidade e força. Além de manter a funcionalidade respiratória, já que o paciente encontra-se fazendo uso de VMI, por meio das técnicas de higiene brônquica, drenagem postural e dispositivo de sucção que auxilie na diminuição das secreções das vias aéreas ${ }^{6-8}$.

Isto é fundamental, visto que como ainda não há cura e o prognóstico da DK é ruim, com uma expectativa de vida entre 17 à 24 meses após a confirmação do diagnóstico ${ }^{3-6,9}$. 
É importante ressaltar que a DK apresenta um risco de $25 \%$ de recorrência para cada nova gestação. Portanto é de suma importância que seja realizado um aconselhamento genético para a família inserida nesse contexto ${ }^{10}$.

O acompanhamento multiprofissional de maneira efetiva proporcionou melhora do quadro clínico com resultados significativos em seu quadro motor e respiratório, com ausência de rigidez e deformidade articular significativa; capacidade respiratória estabilizada; sem histórico de infecções, internações, úlceras de pressão, além da manutenção da amplitude de movimento respiratória.

\section{CONCLUSÃO}

Foi possível identificar que uma investigação diagnóstica rápida e eficaz, aliada ao tratamento multiprofissional bem direcionado pode levar a um melhor prognóstico com aumento da expectativa e qualidade de vida do paciente com DK. Neste caso, a criança veio a óbito com 5 anos e 2 meses devido uma parada cardiorrespiratória

Diante da complexidade no tratamento para essa doença, faz-se necessário que haja um suporte adequado não só para o paciente, mais para a família inserida nessa realidade. Destacando a atuação da equipe multidisciplinar com foco na intervenção fisioterapêutica, que diante dos dados as condutas realizadas pelo profissional de 
fisioterapia proporcionaram uma melhor qualidade de vida

na qual superou a expectativa mencionada na literatura.

\section{REFERÊNCIAS}

1.Kemper AR, Knapp AA, Green NS, Comeau AM, Metterville DR, Perrin JM. Weighing the evidence for newborn screening for earlyinfantile Krabbe Disease. Genet Med 2010;12:539-43. http://dx.doi.org/10.1097/gim.0b013e3181e85721

2.Bongarzone ER. A tribute to the work and life of $\mathrm{Dr}$ Knud $\mathrm{H}$. Krabbe: Advances in genetics, neurophatogenesis, therapies and clinical management of Krabbe' Disease. J Neurosci Res 2016;94:963-4. http://dx.doi.org/10.1002/jnr.23916

3.Gupta A, Poe MD, Styner MA, Panigrahy A, Escolar ML. Regional differences in fiber tractography predict neurodevelopmental outcomes in neonates with infantile Krabbe Disease. Neuroimage Clin 2015;7:792-8. http://dx.doi.org/10.1016/j.nicl.2014.09.014

4.Sano TS. Doença de Krabbe: a importância do diagnóstico precoce para seu prognostico. Einstein (São Paulo) 2012;10:233-5. http://dx.doi.org/10.1590/S1679-45082012000200019

5.Vargiami E, Papathanasiou E, Batzios S, Kyriazi M, Dimitriou E, Anastasiou A, et al. Neuroradiological, neurophysiological and molecular findings in infantile Krabbe Disease: two case reports. Balkan J Med Genet 2016;19:85-90. http://dx.doi.org/10.1515/bjmg2016-0011

6.Kwon JM, Matern D, Kurtzberg J, Wrabetz L, Gelb MH, Wenger DA, et al. Consensus guidelines for newborn screening, diagnosisn and treatment of infantile Krabbe Disease. Orphanet J Rare Dis 2018;13:30. http://dx.doi.org/10.1186/s13023-018-0766-x

7.Orsini Jj, Escolar ML, Wasserstein MP, Caggana M, Adam $\mathrm{PM}$, Ardinger $\mathrm{HH}$, et al. Krabbe Disease. Gene Reviews (Internet), Seattle (WA): University of Washington, Seattle; 1993-2020. 2000. Disponível em: https://www.ncbi.nlm.nih.gov/pubmed/20301416

8. Neves EB. Trends in neuropediatric physical therapy. Frontiers Public Health 2013;1. http://dx.doi.org/10.3389/fpubh.2013.00005 9.Pavuluri P, Vadakedath S, Gundu R, Uppulety S, Kandi V. Krabbe Disease: Reporto $f$ a Rare Lipid Storage and Neurodegenerative Disorder. Cureus 2017;9:1-6. http://dx.doi.org/10.7759/cureus.949 10. Lima DS, Mendonça D, Amparo DM, Marieta L, Simbalista RF, Mota MKF. Doença de Krabbe ou Leucodistrofia da Célula Globóides. Rev Baiana Ped 2007;3:5-9. http://www.sobape.com.br/revistas/Revistabaiana-de-pediatria-vol-3-n-1-2007.pdf 